\title{
Correction: Genomic profiling reveals spatial intra-tumor heterogeneity in follicular lymphoma
}

\author{
Shamzah Araf ${ }^{1,2} \cdot$ Jun Wang ${ }^{3} \cdot{\text { Koorosh Korfi } \mathbb{D}^{1} \cdot \text { Celine Pangault }^{4} \cdot \text { Eleni Kotsiou }}^{1} \cdot$ Ana Rio-Machin $^{1}$. \\ Tahrima Rahim ${ }^{1}$ - James Heward ${ }^{1}$ - Andrew Clear $\mathbb{D}^{1}$ - Sameena Iqbal ${ }^{1}$ - Jeff K. Davies ${ }^{1}$ - Peter Johnson ${ }^{5}$. \\ Maria Calaminici ${ }^{1}$ - Silvia Montoto ${ }^{1} \cdot$ Rebecca Auer $^{1} \cdot$ Claude Chelala $^{3} \cdot$ John G. Gribben $^{1} \cdot$ Trevor A. Graham $^{6}{ }^{6}$. \\ Thierry Fest ${ }^{4} \cdot$ Jude Fitzgibbon ${ }^{1} \cdot$ Jessica Okosun $\mathbb{D}^{1}$
}

Published online: 23 March 2019

(c) The Author(s) 2019

Correction to: Leukemia (2018) 32:1258-1263

https://doi.org/10.1038/s41375-018-0043-y

published online 08 February 2018

In the original version of this article the authors noted an omission in the author affiliations where the university details: Queen Mary University of London was not included in the original affiliation for the majority of the authors. The correct affiliations are as follows

These authors contributed equally: Shamzah Araf, Jun Wang

The original article can be found online at https://doi.org/10.1038/ s41375-018-0043-y.

Shamzah Araf

s.araf@qmul.ac.uk

$\triangle$ Jessica Okosun

j.okosun@qmul.ac.uk

1 Centre for Haemato-Oncology, Barts Cancer Institute, Queen Mary University of London, London, UK

2 Centre for Genomic Health, Queen Mary University of London, London, UK

3 Centre for Molecular Oncology, Barts Cancer Institute, Queen Mary University of London, London, UK

4 UMR INSERM 1236, Université de Rennes, 1, EFS de Bretagne, CHU de Rennes, Rennes, France

5 Cancer Sciences Unit, Cancer Research UK Centre, Southampton, UK

6 Evolution and Cancer Laboratory, Barts Cancer Institute, Queen Mary University of London, London, UK
1. Centre for Haemato-Oncology, Barts Cancer Institute, Queen Mary University of London, London, UK

3. Centre for Molecular Oncology, Barts Cancer Institute, Queen Mary University of London, London, UK

6. Evolution and Cancer Laboratory, Barts Cancer Institute, Queen Mary University of London, London, UK 